\title{
How Can Entrepreneurs Motivate Crowdsourcing Participants?
}

\section{Derek Smith, Mohammad Mehdi Gharaei Manesh, and Asrar Alshaikh}

\author{
"We saw that entrepreneurs could gain the backing") \\ of larger global communities to create tomorrow's \\ innovations and participate in the journey from \\ earlyon.
}

\author{
Myra Landsburg \\ Brand Champion, Grow VC \\ (tinyurl.com/ae5s32t)
}

\begin{abstract}
Crowdsourcing is a way to access a global crowd of talented people and to channel their talent and creative effort towards some useful endeavour. Technology entrepreneurs who may have limited resources, especially during the start-up phase of the business, will be attracted to crowdsourcing as a means to access funding, knowledge, subject matter experts, and resources on a global scale. In this article, we review the published research on crowdsourcing as it relates to motivation, and distil the insights from that research that will be useful to technology entrepreneurs. First, we organize the published research into three streams according to crowd type: i) task-based public crowd, ii) information-exchange public crowd, and iii) employee-based crowd. Next, we identify the motivational drivers common to all streams as well as the motivational drivers that are unique to each stream. Finally, we offer five recommendations for technology entrepreneurs seeking to apply crowdsourcing.
\end{abstract}

\section{Introduction}

When starting up a company, technology entrepreneurs face significant challenges, such as limited funding, lack of resources, and a broad range of difficult technical issues. Access to local funding can be difficult and restrictive. Finding resources on a limited budget can be challenging. Seeking solutions to that last unique technical issue preventing commercialization can be stressful and expensive.

Crowdsourcing is a compelling way to address all of these issues and create connections with talented people and resources from all over the world. These connections present a new opportunity to entrepreneurs to grow their community by selectively adding talent from a target crowd, finding required resources, and developing solutions to technical issues. However, an additional problem for entrepreneurs is to know the right form of motivation to motivate the target crowd, because applying the wrong form of motivation can turn a crowdsourcing initiative into an expensive, timeconsuming distraction that yields poor results.

Crowdsourcing remains a relatively new process and the research into motivation with crowdsourcing tends to be limited to specific and particular applications of crowdsourcing that cannot be sufficiently generalized to be useful to most entrepreneurs. One option for entrepreneurs is to learn from others who have successfully applied crowdsourcing in a particular application and see the specific form of motivation that ensured their success. Entrepreneurs can use these specific forms of motivation when their application is similar to that of the literature. Alternatively, entrepreneurs can use the general principles from the literature and look to find other real-world examples more closely related to their application for guidance. Another option is see- 


\title{
How Can Entrepreneurs Motivate Crowdsourcing Participants?
}

\author{
Derek Smith, Mohammad Mehdi Gharaei Manesh, and Asrar Alshaikh
}

ing what others have done from the perspective of motivating a type of crowd that identifies more generally applicable forms of motivation that ensure success. Entrepreneurs can use these generally applicable forms of motivation when the application is different to that of the literature.

This article makes four contributions. First, it argues that technology entrepreneurs should consider crowdsourcing as a possible tactic to grow their technical community, and get work done quickly, at low cost, and at high quality. Second, it identifies 12 published research articles on motivation in crowdsourcing and summarizes their contents in a form useful to entrepreneurs. Third, it distinguishes between three different types of crowd: i) a task-based public crowd, ii) an information-exchange public crowd, and iii) an employee-based crowd - and it summarizes the differing motivational drivers reported for each type. Fourth, it provides five recommendations to entrepreneurs and managers seeking to effectively motivate crowds.

\section{Crowdsourcing and Motivation}

Jeff Howe (2006; tinyurl.com/q28us) initially identified and described crowdsourcing as follows:

"Welcome to the age of the crowd. Just as distributed computing projects like UC Berkeley's SETI@home have tapped the unused processing power of millions of individual computers, so distributed labor networks are using the Internet to exploit the spare processing power of millions of human brains... But now the productive potential of millions of plugged-in enthusiasts is attracting the attention of old-line businesses, too...Hobbyists, part-timers, and dabblers suddenly have a market for their efforts, as smart companies in industries as disparate as pharmaceuticals and television discover ways to tap the latent talent of the crowd."

Crowdsourcing (tinyurl.com/yom4t8) has become a modern day form of outsourcing; it brings an endeavour to a globally distributed group of unrelated people with varying degrees of motivational needs, skills, and talent. Crowdsourced endeavours have included both simple and complex tasks relating to problem solving, design, and product development. Crowdsourcing provides an entrepreneur with access to resources on a global scale through the Internet. These resources may be much more cost effective for the entrepreneur as well as valuable when looking to find and engage the best people to solve problems and add value.
However, asking the crowd for help is only part of the challenge; an entrepreneur must also encourage members of that crowd to step forward. Finding and applying the right type of motivation is essential for success in crowdsourcing. Two primary types of motivation described in the literature are extrinsic and intrinsic motivation (Leimeister et al., 2009: tinyurl.com/adzjqv6; Hossain, 2012: tinyurl.com/apnqdk6). Extrinsic motivation is external, or outside an individual. Extrinsic motivation provides an incentive that the task itself does not provide to the crowd member, such as money or prizes. Intrinsic motivation is internal to an individual and provides benefit to the crowd member who contributes to the actual crowdsourcing task. An example of intrinsic motivation is enjoyment.

Three examples of motivational approaches in crowdsourcing are provided below.

\section{Lufthansa}

Some companies have used crowdsourcing to engage customers to shape the future of a business segment. An example is Lufthansa's Air Cargo Innovation Challenge for Customer Service (tinyurl.com/ago54fh). Lufthansa was looking for creative ideas about the future form and function of customer service as it related to cargo and in particular the touch points between a customer and Lufthansa customer service representatives. Lufthansa also seized the opportunity to find "out of the box ideas" from the crowd. Members registered to join this crowdsourcing community and created a pool of ideas for consideration by a corporate jury. The motivational drivers used by Lufthansa to motivate the crowd were three different prizes that included training in a flight simulator located at the Frankfurt International Airport and different amounts of air miles (i.e., points to be redeemed against future passenger flights). The top three ideas provided customer insight into a certification program to create trust and loyalty, a CargoTRIS idea to educate people about Lufthansa Cargo, and a CargoPedia idea to build a cargo knowledge base with specific knowledge.

\section{Bombardier}

Crowdsourcing can also engage customers to participate in the design of a product. An example is Bombardier's innovation contest (tinyurl.com/yfoytew), which sought ideas relating to the future of train interiors. Bombardier was looking for innovative features to be incorporated into the interior based upon insight from leisure passengers, business travelers, and everyday passengers. Participants registered to join this crowd- 


\title{
How Can Entrepreneurs Motivate Crowdsourcing Participants?
}

\author{
Derek Smith, Mohammad Mehdi Gharaei Manesh, and Asrar Alshaikh
}

sourcing community and a corporate jury considered the submissions. The motivational drivers selected by Bombardier for the top 10 submissions in two categories were different levels of cash prizes from 2,000 Euros to 200 Euros as well as Netbook computers. The two categories related to the coach interior and a new seat design. The winning designs provided focus to Bombardier, insight into the passenger needs, and a high level of innovation for the next train product.

\section{Zooniverse}

Crowdsourcing can also engage members from the public to participate in scientific research in situations where funding and staff are limited. Zooniverse (zooniverse.org) is an online science and research site that applies crowdsourcing to citizen-based science projects in a number of different categories. One project relates to studying photos from Mars to determine weather patterns. The group of researchers on this project was too small to effectively review the multitude of images in the photo library while remaining within the time constraints and scope of the project. Volunteers are assisting the researchers with visual identification of particular features on the images such as "fans" and "blotches" on the Martian surface, which are indicative of wind direction and speed. The primary motivational driver for the volunteers is being allowed access to amazing satellite images from Mars. As of January 2013, over 60,000 volunteers had reviewed and reported on more than 3 million photos.

\section{Literature Review}

Our review of the crowdsourcing literature began with a search in the Business Source Complete (BSC; tinyurl.com/22teqry) database on the keyword "crowdsourcing". When restricted to full-text scholarly journals, the database query identified 103 individual articles, with the earliest publication in 2006, the same year as Howe's original crowdsourcing article. A review of the abstracts, keywords, and introduction of the 103 articles identified a subset of 11 articles about motivation. We examined the references of these articles and added one additional article to this set for a total of 12 articles. Articles unrelated to motivation were set aside.

We speculate that the literature on crowdsourcing motivation is limited, in part, because the topic is relatively new. Motivation has long been of a topic of central interest to researchers in psychology, economics, and organizational behaviour (e.g., Hertzberg, 1968; tinyurl.com/a3ojrnh), but only recently have researchers turned their attention to crowds.
The 12 articles were published in 11 different journals and conference proceedings. The journals vary widely in disciplinary focus, including marketing, information systems, and innovation. The articles focus on specific applications of crowdsourcing such as designing Tshirts, exchanging technical information in a community, and creating ideas. Table 1, Table 2, and Table 3 present summaries of the field settings, research designs, and unique contributions of the 12 articles.

Motivation based upon the specific application of crowdsourcing varied significantly, suggesting that motivation is unique to the application. However, we were able to identify three crowd types based on similarities in motivational approaches and contexts: i) task-based public crowds, ii) employee-based crowds, and iii) information-exchange public crowds These groups differed from each other with respect to the participants and function of the crowds examined. Organizing the literature in this way revealed insight into groupings of motivational categories and drivers common to each type of crowd. It also revealed insight into a contrasting view of each individual finding in the literature and uncommon motivational categories and drivers. Each of the three crowd types is defined and described in the following subsections.

\section{Task-based public crowds}

Public task-based crowds perform a specific task or a set of tasks. There are few or no relationships between the crowd participants, who each contribute using their individual abilities. We identified seven articles in this literature stream (Table 1).

The field settings examined in this research include six intermediary companies offering a crowdsourcing service to customers or corporations and two companies that use internal crowdsourcing capabilities as part of their business model. The types of design tasks in this stream relate to electronics, product design, digital media products, T-shirts, graphics, advertisement, and websites.

Motivational drivers examined in these articles include: immediate financial payment (of varying amounts), skills improvement, enjoyment and fun (of varying type), and community-related motivations. Technology entrepreneurs involved in similar tasks could consider motivating their own crowds in similar ways. However, it is important to note that financial payment might not be the best way to motivate a crowd (Antikainen et al., 2010: tinyurl.com/aj4zn3e; Bogers and West, 2012: tinyurl.com/aevdk4v) because other forms of motivation can be more important. 


\section{How Can Entrepreneurs Motivate Crowdsourcing Participants?}

Derek Smith, Mohammad Mehdi Gharaei Manesh, and Asrar Alshaikh

Table 1. Published studies of task-based public crowds

\begin{tabular}{|c|c|c|c|}
\hline Author (Year) & Journal or Conference & Field Setting(s) & Research Design \\
\hline $\begin{array}{l}\text { Antikaninen et al. (2010) } \\
\text { tinyurl.com/aj4zn3e }\end{array}$ & $\begin{array}{l}\text { European Journal of } \\
\text { Innovation Management }\end{array}$ & $\begin{array}{l}\text { Three } \\
\text { crowdsourcing } \\
\text { intermediary } \\
\text { companies: } \\
\text { Crowdspirit, } \\
\text { FelloForce, Owela }\end{array}$ & $\begin{array}{l}\text { Multiple case } \\
\text { study, } \\
\text { email } \\
\text { questionnaires, } \\
\text { archival } \\
\text { documents }\end{array}$ \\
\hline
\end{tabular}

\section{Contribution}

Identified motivational drivers of open innovation communities and tasks related to product design and development. Motivational drivers included interesting objectives, open and constructive atmosphere, influencing better products/services, synergy, sense of cooperation, fun, community (identification, love), and sense of efficiency.

\begin{tabular}{lll}
\hline Brabham (2010) & Information, & A crowdsourced- \\
tinyurl.com/b9ggaur & Communication \& Society & based company: \\
& Threadless
\end{tabular}

Instant messaging Identified motivational drivers relating to a
interviews with T-Shirt design company. Motivational members in a drivers included addiction, pastime, fun, community cash payment, freelance opportunities, improving skills, and knowledge gathering.

\begin{tabular}{llll}
\hline $\begin{array}{l}\text { Bogers \& West (2012) } \\
\text { tinyurl.com/ba3gg3x }\end{array}$ & $\begin{array}{l}\text { Creativity and Innovation } \\
\text { Management }\end{array}$ & $\mathrm{n} / \mathrm{a}$ & $\begin{array}{l}\text { Literature review } \\
\text { of open- and user- } \\
\text { innovation } \\
\text { research }\end{array}$ \\
\hline $\begin{array}{l}\text { Muhdi \& Boutellier (2011) } \\
\text { tinyurl.com/ay2u646* }\end{array}$ & $\begin{array}{l}\text { International Journal of } \\
\text { Innovation Management }\end{array}$ & $\begin{array}{l}\text { A Swiss } \\
\text { crowdsourcing } \\
\text { intermediary } \\
\text { company: } \\
\text { Atizo }\end{array}$ & $\begin{array}{l}\text { Electronic survey } \\
\text { of members in a } \\
\text { community }\end{array}$ \\
& &
\end{tabular}

Distinguished between motivation for cash and no cash innovation

\begin{tabular}{|c|c|c|c|c|}
\hline $\begin{array}{l}\text { Busarovs (2011) } \\
\text { tinyurl.com/abb3rk9 }\end{array}$ & $\begin{array}{l}\text { Journal of Business } \\
\text { Management }\end{array}$ & $\mathrm{n} / \mathrm{a}$ & $\begin{array}{l}\text { Conceptual; } \\
\text { literature review of } \\
\text { prior research on } \\
\text { motivation }\end{array}$ & $\begin{array}{l}\text { Examined the relationship between type of } \\
\text { task (routine, complex, or creative), amount } \\
\text { of cash payment (no cash, pennies, dollars, } \\
\text { millions of dollars), and expected outcomes }\end{array}$ \\
\hline $\begin{array}{l}\text { Kaufmann et al. (2011) } \\
\text { tinyurl.com/bk6eeec }\end{array}$ & $\begin{array}{l}\text { Seventeenth Americas } \\
\text { Conference on } \\
\text { Information Systems }\end{array}$ & $\begin{array}{l}\text { A crowdsourcing } \\
\text { intermediary } \\
\text { company: } \\
\text { Mechanical Turk. }\end{array}$ & $\begin{array}{l}\text { Online survey } \\
\text { posted as a task to } \\
\text { crowdsourcing } \\
\text { website; } \\
\text { respondents paid } \\
30 \text { cents for } \\
\text { participation }\end{array}$ & $\begin{array}{l}\text { Identified motivational categories and } \\
\text { drivers of crowdsourced workers. Three } \\
\text { extrinsic categories: immediate payoffs, } \\
\text { delayed payoffs, and social motivation. Two } \\
\text { intrinsic categories: enjoyment-based and } \\
\text { community-based. Drivers included skill } \\
\text { variety, task identity, task autonomy, direct } \\
\text { feedback from the job, pastime, } \\
\text { communication identification, social } \\
\text { contract, payment, signaling, human } \\
\text { capital advancement, action significance by } \\
\text { external values, action significance by } \\
\text { external obligations, and indirect feedback } \\
\text { from the job. }\end{array}$ \\
\hline
\end{tabular}

\footnotetext{
* Muhdi and Boutellier (2001; http://dx.doi.org/10.1142/S1363919611003477) appear in both Table 1 and Table 2 because they cover field settings of two different crowd types.
} 


\section{How Can Entrepreneurs Motivate Crowdsourcing Participants?}

Derek Smith, Mohammad Mehdi Gharaei Manesh, and Asrar Alshaikh

Table 2. Published studies of employee-based crowds

\begin{tabular}{llll} 
Author (Year) & Journal or Conference & Field Setting(s) & Research Design \\
\hline $\begin{array}{llll}\text { Hossain (2012) } \\
\text { tinyurl.com/apnqdk6 }\end{array}$ & $\begin{array}{l}\text { International Conference } \\
\text { on Innovation }\end{array}$ & $\mathbf{n}$ & $\begin{array}{l}\text { Conceptual; } \\
\text { Management and } \\
\text { Technology Research }\end{array}$ \\
& & & $\begin{array}{l}\text { literature review } \\
\text { of prior research } \\
\text { on crowdsourcing } \\
\text { platforms }\end{array}$
\end{tabular}

\section{Contribution}

Assembled motivational drivers into

groups based upon the literature to include three categories: financial, social, and organization. Motivational drivers included benefits, job opportunities, personal needs, career options, marketing oneself, professional prestige, responsibilities, recruiting, collaboration, ego, experience, frustration, knowledge gathering, networking, recognition, power, privilege attainment, publicity, reputation, skill development, social, status, charity, competence, desire to solve, enjoyment, fun, pleasure, self satisfaction, altruism, autonomy, belongingness, community drives, identification, self determination, ideas, learning, pride, and self fulfillment.

\begin{tabular}{|c|c|c|c|c|}
\hline $\begin{array}{l}\text { Stewart et al. (2009) } \\
\text { tinyurl.com/b67msrm }\end{array}$ & $\begin{array}{l}\text { ACM SIGKDD Workshop } \\
\text { on Human Computation } \\
\text { (HDD-HCOMP'09) }\end{array}$ & $\begin{array}{l}\text { A language } \\
\text { translation task } \\
\text { within a multinational } \\
\text { ICT and service } \\
\text { company: IBM }\end{array}$ & $\begin{array}{l}\text { Quantitative } \\
\text { survey; } \\
\text { hypothesis tests }\end{array}$ & $\begin{array}{l}\text { Identified motivational drivers for an } \\
\text { employee based type of task to include } \\
\text { social contract, positive impact on the } \\
\text { community and the world, reward, } \\
\text { learning, fun, and brand image }\end{array}$ \\
\hline $\begin{array}{l}\text { Muhdi \& Boutellier (2011)* } \\
\text { tinyurl.com/ay2u646 }\end{array}$ & $\begin{array}{l}\text { International Journal of } \\
\text { Innovation Management }\end{array}$ & $\begin{array}{l}\text { A Swiss bank: } \\
\text { PostFinance }\end{array}$ & $\begin{array}{l}\text { Electronic survey } \\
\text { of participants }\end{array}$ & $\begin{array}{l}\text { Identified motivational factors of } \\
\text { employees in a bank. This included six } \\
\text { categories such as social aspect, } \\
\text { competition, learning, sense of efficiency, } \\
\text { rewards, and platform. Motivational } \\
\text { drivers included social contract, sense of } \\
\text { efficiency, rewards and learning. }\end{array}$ \\
\hline
\end{tabular}

${ }^{*}$ Muhdi and Boutellier (2001; http://dx.doi.org/10.1142/S1363919611003477) appear in both Table 1 and Table 2 because they cover field settings of two different crowd types.

Table 3. Published studies of information-exchange crowds

\begin{tabular}{llll} 
Author (Year) & Journal or conference & Field setting(s) & Research design \\
\hline $\begin{array}{l}\text { Toubia (2006) } \\
\text { tinyurl.com/anfffu }\end{array}$ & Marketing Science & $\begin{array}{l}\text { Controlled simulation } \\
\text { of an ideas game }\end{array}$ & $\begin{array}{l}\text { Experimental } \\
\text { design; } \\
\end{array}$ \\
& & $\begin{array}{l}\text { manipulation of } \\
\text { motivation drivers } \\
\text { and measurement }\end{array}$ \\
& & of outcomes
\end{tabular}

\begin{tabular}{|c|c|c|c|c|}
\hline $\begin{array}{l}\text { Leimeister et al. (2009) } \\
\text { tinyurl.com/adzjqv6 }\end{array}$ & $\begin{array}{l}\text { Journal of Management } \\
\text { Information Systems }\end{array}$ & $\begin{array}{l}\text { Competition hosted } \\
\text { by a multinational } \\
\text { enterprise software } \\
\text { company: SAP's } \\
\text { SAPiens Ideas } \\
\text { Competition }\end{array}$ & Field study & $\begin{array}{l}\text { Identified motivational drivers of an } \\
\text { Internet-based ideas competition, } \\
\text { including prizes, career options, } \\
\text { marketing oneself, recognition (peer, } \\
\text { organizer) and knowledge (experts, } \\
\text { mentors, peers) }\end{array}$ \\
\hline
\end{tabular}

\begin{tabular}{ll}
\hline Wasko \& Faraj (2000) & Journal of Strategic \\
tinyurl.com/a4sqcbw & Information Systems
\end{tabular}

Illustrated that participates could be motivated differently to create new ideas or to build upon existing ideas. The motivational drivers included prizes and payments.
Three online Usenet communities: $\mathrm{C}++$, object oriented design, and databases

\begin{tabular}{ll}
$\begin{array}{l}\text { Competition hosted } \\
\text { by a multinational } \\
\text { enterprise software } \\
\text { company: SAP's } \\
\begin{array}{l}\text { SAPiens Ideas } \\
\text { Competition }\end{array}\end{array}$ & Field study \\
\hline $\begin{array}{l}\text { Three online Usenet } \\
\text { communities: }\end{array}$ & $\begin{array}{l}\text { Examined } \\
\text { messaging activity } \\
\text { C++, object oriented } \\
\text { design, and databases time } \\
\text { (archival online } \\
\text { records); email } \\
\text { survey of } \\
\text { participants }\end{array}$ \\
&
\end{tabular}
Identified motivational drivers for knowledge exchange and sharing to include fun, altruism, community identification, sense of efficiency, job opportunities, rewards, and learning
Identified motivational drivers of an including prizes, career options, organizer) and knowledge (experts, mentors, peers)




\title{
How Can Entrepreneurs Motivate Crowdsourcing Participants?
}

\author{
Derek Smith, Mohammad Mehdi Gharaei Manesh, and Asrar Alshaikh
}

\section{Employee-based crowds}

Participants in a corporate, employee-based crowd are employed by the host company. We identified three articles in this stream (Table 2). Two articles examined large-company field settings: one was based in Switzerland (Muhdi and Boutellier, 2011; tinyurl.com/ay2u646) and the other examined a multinational corporation (Stewart et al., 2009; tinyurl.com/b67msrm). The third article (Hossain, 2012; tinyurl.com/apnqdk6) is a literature review on motivation and incentives. The crowdsourcing tasks examined in this literature stream included internal idea generation and language translations.

Motivational drivers in these articles include immediate payment of rewards, such as peer recognition, career advancement, and professional development.

\section{Information-exchange public crowds}

This type of crowd includes participants seeking technical information as well as participants providing technical information, and these roles are interchangeable. Some tasks may also require creativity in addition to technical information.

We identified three articles in this stream (Table 3). Two articles examined field settings; one was an ideasbased community organized around a companysponsored contest, and the other was a knowledgebased community anchored around online Usenet groups about computer programming and databases. The third article was a controlled experiment by marketing researchers who could manipulate the points system used to reward participants for contributions and thus shape crowd behaviour. In this last article, one point system resulted in more new ideas, while a second point system resulted in more ideas that built upon existing ideas.

Motivational drivers examined in these articles include access to technical experts to solve problems, learning, fun, and being part of a community.

\section{Recommendations for Entrepreneurs}

From a close reading of the published research on crowdsourcing motivation, and from looking closely at the similarities and differences in the field settings and results of various studies, we offer five recommendations for technology entrepreneurs seeking to gain global access to resources from crowdsourcing.

\section{Learn from what others have done by identifying and using known motivational drivers to achieve early success}

Tables 1, 2, and 3 provide a starting point for identifying motivational drivers. If a project is similar to one of the field settings previously examined in the literature, then the entrepreneur should first consider the motivational drivers used to motivate crowd. For example, if a crowdsourced project relates to open innovation, then the articles by Antikainen and colleagues (2010; tinyurl.com/aj4zn3e) and Muhdi and Boutellier (2011; tinyurl.com/ay2u646) may provide some guidance. If the project relates to crowdsourcing workers, then the article by Kaufmann and colleagues (2011; tinyurl.com/ bk6eeec) might be insightful.

If a crowdsourcing project differs greatly from the field settings in in the literature, then the entrepreneur should consider the type of crowd they want to build. For example, prior research on task-based public crowds has examined immediate financial payment, skills improvement, enjoyment and fun, and community-related motivations (Kaufmann et al., 2011: tinyurl.com/bk6eeec; Brabham, 2010: tinyurl.com/b9ggauv; Busarovs, 2011: tinyurl.com/abb3rk9; Antikainen et al., 2010: tinyurl.com/aj4zn3e; Muhdi and Boutellier, 2011: tinyurl.com/ay2u646). Prior research on technical information based crowds has examined access to people for learning, and enjoyment and fun (Wasko and Faraj, 2000: tinyurl.com/a4sqcbw; Leimeister et al., 2009: tinyurl.com/adzjqv6). Prior research on employee-based crowds has examined rewards of immediate payment and access to people technical experts for learning (Muhdi and Boutellier, 2011: tinyurl.com/ay2u646; Stewart et al., 2009; tinyurl.com/b67msrm).

Crowdsourcing is a new research area with relatively few published studies, thus the past experience of others should be suggestive rather than definitive. Also, many implementation details must still be decided. After identifying motivational drivers, entrepreneurs and managers need to identify the motivational details such as the range or amount of payment, the type of rewards, and the calibre of people or makeup of the community.

\section{Create a selection and range of motivational drivers, and learn by varying those drivers}

Research suggests there is no single combination of motivational drivers generally applicable to all crowds. Managers offering a selection and range of motivational drivers and varying the implementation details over time can learn more quickly about what works for their particular situation. In the examples presented earlier, Bombardier varied the dollar amount of cash incentives, whereas Lufthansa varied the amount of the air miles awarded. 


\title{
How Can Entrepreneurs Motivate Crowdsourcing Participants?
}

\author{
Derek Smith, Mohammad Mehdi Gharaei Manesh, and Asrar Alshaikh
}

The literature also suggests that motivational drivers may be changed during an active crowdsourcing project to achieve different results (Toubia, 2006; tinyurl.com/an5fpfu) - a technique we call adaptive motivation. For example, the Zooniverse project studying photos from Mars employed different motivational drivers to either focus the crowd on specific photographs or to have the crowd revisit a previously studied photograph.

\section{Select implementation details that are matched to the} particular context and identify relevant motivation drivers The research suggests the most effective motivational driver is only revealed by breaking down or expanding each aspect of motivation. For example, a form of extrinsic motivation is immediate payoffs, which can take different forms, including cash payments, career options, prizes, and points. Each form of immediate payoff can be set at different levels: different amount of cash, size and selection of prizes, and number of points. In the example of Lufthansa, the extrinsic immediate payoff was prizes with the specific aspects of a training session in a flight simulator and differing amounts of air miles. In the case of Bombardier, the extrinsic immediate payoffs were varying levels of financial reward.

\section{Consider the geographical and cultural diversity of the target crowd}

Crowdsourcing can attract participation from individuals located in different countries with different cultures. By understanding the mix of your potential crowd, entrepreneurs and managers may identify and select motivational drivers to target attracting members to the crowd to form an initial community or adding different members to the community during the course of the crowdsourcing. For example, motivational drivers that work globally may not work locally and may be country specific. For example, Busarovs (2011; tinyurl.com/ abb3rk9) indicates that financial payment on the order of pennies will be sufficient to motivate participants in some communities, whereas other communities will require payment on the order of dollars.

\section{Employ multiple motivational drivers to obtain the full benefit of crowd diversity}

The crowdsourcing motivational literature tells us that different individuals are motivated differently by different incentives. To motivate a diverse crowd, it follows that technology entrepreneurs should employ multiple motivation drivers that appeal to different potential participants in the type of crowd. Beyond this suggestion, however, prior research offers little prescriptive advice on specifically how to develop an effective mix of crowdsourcing motivation drivers. This is a promising and important area for future work.

\section{Conclusion}

This article reviewed the published research on crowdsourcing and motivation, presented the content and contribution of that research in a series of tables organized by crowd type, and proposed five actions for technology entrepreneurs seeking to benefit from crowdsourcing. Based on our close reading of the research, we recommend that technology entrepreneurs learn from what others have done by beginning from known motivational drivers, learn quickly through experimentation by varying the implementation details, select implementation details that are matched to their particular context, consider the geographical and cultural diversity of the target crowd, and employ multiple motivation drivers to obtain the full benefit of crowd diversity.

Entrepreneurs need to select and apply the right form of motivation to motivate target crowds in crowdsourcing. If their particular application of crowdsourcing is similar to one of the specific applications described in the tables in this article, then entrepreneurs may select the corresponding form of motivation to successfully motivate their target crowd, seeking further detail from the literature as required. If their particular application of crowdsourcing is different to the applications described in the tables, then entrepreneurs should select the table that best matches the type of crowd they wish to motivate and apply the general approaches used by those applications. In both cases, entrepreneurs should also seek out additional realworld examples of applications similar to their own, while applying the principles and recommendations described here to their interpretation of those examples.

Successful motivation of the target crowd will increase the likelihood of success with crowdsourcing and will provide entrepreneurs with a way to solve significant challenges such as quests for funds, resources, and solutions to unique technical issues for the commercialization of their products. 


\section{How Can Entrepreneurs Motivate Crowdsourcing Participants?}

Derek Smith, Mohammad Mehdi Gharaei Manesh, and Asrar Alshaikh

\section{About the Authors}

Derek Smith is the founder and principal of Magneto Innovention Management, an intellectual property consulting firm that assists entrepreneurs and small businesses to navigate and grow their international patent portfolios. He has over 20 years of experience working as an intellectual property management consultant and patent agent for IBM Canada, Bell Canada and, most recently, Husky Injection Molding Systems where he was Director, Global Intellectual Property. Prior to entering the field of intellectual property, he was an advisory engineer at IBM Canada where he was involved in a variety of leading-edge software development projects. Derek is currently a graduate student in the Technology Innovation Management (TIM) program at Carleton University in Ottawa, Canada. He also holds a BEng degree in Systems and Computer Engineering from Carleton University and is a registered patent agent in both Canada and the United States.

Mohammad Mehdi Gharaei Manesh is a graduate student in the Technology Innovation Management (TIM) program at Carleton University in Ottawa, Canada. He holds an MBA degree from Carleton University's Sprott School of Business and has a degree in Biomedical Engineering from Tehran Polytechnic University. He has 5 years of working experience in a medical equipment company and his main area of interest relates to crowdsourcing and international business.

Asrar Abdulqader Alshaikh is a graduate student in the Technology Innovation Management (TIM) program at Carleton University in Ottawa, Canada. She holds a Bachelor of Accounting degree from King Abdulaziz University in Jeddah, Saudi Arabia. Her working experience includes customer service in a sale for distribution and communication company as well as working for the Alahli Bank (NCB) in Jeddah, Saudi Arabia. 